\title{
ENTREVISTA AL PROFESOR EMÉRITO DOCTOR SERgIO GARCÍA RAMÍREZ ${ }^{1}$
}

\section{ABRIL USCANGA BARRADAS}

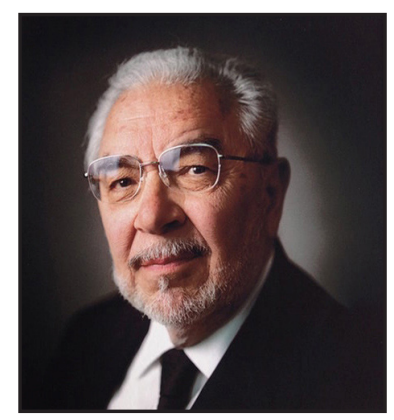

Sergio García Ramírez es Doctor en Derecho magna cum laude por la Universidad Nacional Autónoma de México. Profesor Emérito de la misma Universidad e investigador nacional emérito del Sistema Nacional de Investigadores (SNI). También es investigador en el Instituto de Investigaciones Jurídicas de la UNAM. Fue juez de la Corte Interamericana de Derechos Humanos (19982009), en donde fungió como Presidente entre 2004 y 2008. Fue Presidente (fundador) de la Junta de Gobierno del Instituto Nacional de Ciencias Penales, miembro del Consejo Consultivo de la Comisión Nacional de los Derechos Humanos y presidente de la Academia Mexicana de Ciencias Penales. Ha desempeñado diversos cargos públicos, entre ellos: Procurador General de Justicia del Distrito Federal, Secretario del Trabajo y Previsión Social, Procurador General de la República y Presidente (fundador) del Tribunal Superior Agrario. Es autor de numerosos libros y artículos sobre temas jurídicos, políticos y sociales. Es Doctor honoris causa por diversas instituciones mexicanas y extranjeras. Correo: <sgriijunam@gmail. com>. ORCID: <https://orcid.org/0000-0002-9164-8464>.

1 Este documento constituye una transcripción de la entrevista realizada. Se ha revisado sin alterar el estilo coloquial propio de una conversación, considerando que esta característica enriquecería el texto que se presenta al lector. La entrevista fue realizada con la colaboración de Diana Saldaña Martinez y Javier Cancino Jiménez. 
Entrevista al Doctor Sergio García Ramírez

Sergio García Ramírez: En primer lugar, agradezco que me ha permitido tener presencia en la Revista del Posgrado en Derecho de la UNAM a través de un artículo. Me alegra mucho por la calidad de la revista y por la gentileza de quienes se encuentran a cargo de ella, particularmente la directora, y por hallarme de nueva cuenta en un foro, en este caso de una revista de nuestro posgrado en el cual figura la Facultad de Derecho y el Instituto de Investigaciones Jurídicas, además me agrada mucho acompañar a la Dra. Palacios en esta aparición en la escena de esta nueva sección. Es muy estimulante y grato, aprecio mucho el esfuerzo que ustedes hacen y me sumo con toda alegría a él.

Abril Uscanga Barradas: Muchas gracias Doctor, es un esfuerzo de jóvenes que intentamos también aportar algo a la Universidad y deseamos que así sea y, para bien.

Doctor, muchísimas gracias por haber aceptado y para empezar me gustaría que nos hablara un poco acerca de su trayectoria académica, una trayectoria que refleja la labor de un jurista, un docente, un investigador, un servidor público, en fin, es impacte y ahora, más recientemente desde su nombramiento o designación como profesor emérito, la mayor de las distinciones que tiene la Universidad $\mathrm{Na-}$ cional Autónoma de México, por supuesto deseamos saber un poco más de usted, desde sus palabras. Creo que podría ayudarnos si nos comenta un poco acerca del inicio de esta trayectoria ¿Cómo fue?

SGR: Bueno, gracias por el interés que manifiestan en mi trayectoria académica, que ha sido larga porque mi vida también ha sido larga. Buena parte de mi vida se ha dedicado al quehacer académico, aparte de que también he sido servidor público pero siempre he tratado de conciliar el servicio público en el que me he desempeñado con la actividad académica, la cual es una parte importante de mi vida y que además se encuentra entrañada en mi vocación. Yo inicie mis tareas académicas recién obtenido el título 
de licenciado en Derecho. Me hizo el favor de invitarme a ejercer la catedra, entonces como profesor interino, quien era director de la Facultad de Derecho, mi maestro, el Dr. Cesar Sepúlveda, maestro de Derecho Internacional Público. Así inicie mi desempeño como profesor. Con el tiempo obtuve la catedra por concurso y también me incorporé en el Instituto de Investigaciones Jurídicas, que en aquel entonces se llamaba Instituto de Derecho Comparado y que tenía su sede al lado de la Facultad de Derecho, en la Torre de Humanidades. Así comencé mis tareas que realmente no se han interrumpido. Por supuesto, he tenido lapsos largos de quehacer como servidor público, pero como acabo de decir he procurado mantener en todo momento mi vinculación estrecha con mi Universidad, la Nacional Autónoma de México, con mi Facultad, la de Derecho, y con el Instituto en el que también estoy adscrito, que es el de Investigaciones Jurídicas. Estimo haber conseguido esa constancia, esa cercanía. Últimamente me he visto favorecido con una generosa iniciativa del Director de la Facultad de Derecho y del Consejo Técnico de la Facultad en mi favor, generosa ciertamente e inmerecida, pero recibida con gran beneplácito y con enorme satisfacción que es la de figurar como profesor emérito de la Universidad Nacional Autónoma de México, un privilegio que yo realmente nunca esperé tener, que nunca esperé recibir y que ha llegado merced a la buena disposición de colegas y amigos. Yo reconozco ante todo la buena disposición para obtener ese emeritazgo y ojala algún día pueda ser realmente acreedor a él.

AUB: Sin duda lo es Doctor, de hecho muchos esperábamos su emeritazgo y es muy bien recibido no solo por la comunidad de la Facultad de Derecho sino la comunidad que se ha visto totalmente influenciada por su pensamiento, usted tiene una gran cantidad de publicaciones, de obras en diversas áreas que ya las comentaremos en su momento, permítame preguntar, ¿Cómo ha hecho para compatibilizar la academia con la práctica? Como ya lo ha dicho ha tenido una gran trayectoria en el servicio público y la verdad es que 
no siempre se logra el mantener la dualidad entre lo académico y lo práctico y usted lo ha logrado de una manera maravillosa ¿Cómo podría un jurista llegar a tener esa capacidad?

SGR: La verdad no me ha sido difícil porque tengo esa doble vocación. La vocación de funcionario público no me ha abandonado aun cuando haya terminado ya mi etapa como servidor público, y la vocación académica ha persistido desde el principio. Curse el doctorado en Derecho con el propósito de hacer vida académica, no se trataba de tener un diploma o constancia de estudios superiores, sino de practicar la vida académica, para eso me incorpore como alumno de la entonces División de Estudios Superiores en donde el secretario era Don Emilio Rabasa, y fue ahí donde cursé el doctorado en los términos que en ese entonces se estipulaban, obtuve el doctorado de una forma para mi muy satisfactoria y seguí adelante. En forma coincidente recibí invitaciones para actuar en cuestiones de servicio público, inicialmente en el ámbito penitenciario, que me llamaba poderosamente la atención. En el curso de la carrera surgió o se acentuó mi interés por los temas penales tan vinculados con la situación y los problemas del ser humano; hay una relación muy estrecha entre las angustias del ser humano, las necesidades, sus requerimientos, y el sistema penal en amplio sentido, la criminología, la penología, el derecho penal, el procedimiento penal. Al recibir yo estas invitaciones comencé a trabajar en el ámbito penitenciario, primero en la Ciudad de México, en la Penitenciaria del Distrito Federal que entonces era un establecimiento relativamente nuevo, y más adelante en el Estado de México como director del Centro Penitenciario, pero insisto sin abandonar nunca la cercanía con la Universidad. Esto me permitió mantener mi estudio, mi reflexión, a propósito de los temas jurídicos y tratar de aplicar ese estudio, esa reflexión a la práctica cotidiana, primero al servicio penitenciario y después de otras tareas también de la administración pública, y también recoger a la inversa mis experiencias como servidor público para poderlas proyectar en mi quehacer como profesor e in- 
vestigador universitario, depositar esas experiencias en libros, en artículos, conferencias. A mí esto me resulto muy natural, porque es mi vocación, vocación doble de dos líneas que son perfectamente compatibles y ninguna de las dos es producto de mi imaginación, ambas son parte de mi experiencia y de mi razón de ser, de vivir y de trabajar

AUB: Y en ese, digamos, esa trayectoria que ya la podemos visualizar en este momento, yendo un poco más hacia atrás ¿Cuándo decidió estudiar Derecho? ¿Es una vocación de siempre?

SGR: Un poco para atrás, en la primera etapa de juventud, que es cuando tome la decisión, me encontraba en las puertas de la preparatoria y había necesidad de elegir cual era el área en que yo me inscribiría. Me costó algún trabajo, pero no mucho, resolver. Debo decir que no tenía muy claro el por qué de mi dedicación y mi destino como abogado. No me podía contar como una persona de una vocación así muy intensa, muy recia y exclusiva hacia la abogacía, pero tampoco hacia otra materia u otra disciplina. Llegado el momento de decidir y quizá por antecedentes familiares, tal vez por lo que había visto o vivido en relación con la abogacía, hizo que me inclinara por inscribirme en el ámbito de humanidades y específicamente en el de Derecho; no me arrepiento de haber optado por ese camino. Por supuesto que en el curso de los estudios, probablemente a ustedes les ha pasado, uno se enfrenta a muchas dudas, inquietudes, interrogantes, y se pregunta si ese camino es el más adecuado y dentro de ese camino cuál puede ser la vertiente atractiva a la que uno pretenda destinar su vida. Bueno, hice la carrera en términos adecuados, no tuve tropiezos graves, incertidumbre a veces sí, dudas por supuesto, la cursé en términos adecuados. Me recibí de Licenciado en Derecho con una tesis que tenía que ver con temas penitenciarios, se llamaba "Represión y tratamiento penitenciario". La presenté y tuvo un buen resultado. Inmediatamente inicié los estudios de posgrado, en aquel entonces no se estudiaba una maestría como etapa intermedia entre la licenciatura y el 
doctorado, inmediatamente se iba al doctorado en Derecho, así que curse el doctorado y tuve profesores, como los tuve también en la licenciatura, de primer nivel, verdaderamente maestros eminentes en un doble sentido, por su conocimiento jurídico y capacidad como juristas, por su trascendencia en el pensamiento jurídico mexicano e incluso internacional, pero además importantes como seres humanos para mí, personas que me brindaron su ayuda, yo diría que me tendieron la mano profesional y académicamente y que me ayudaron a definir mi rumbo y después a avanzar en el cumplimiento de esas definiciones. Tuve maestros muy generosos. Puedo mencionar con gran agrado haber tenido profesores de gran talla académica y humana que me abrieron la puerta, a veces se dice que los mayores cierran la puerta a los jóvenes, yo espero no sea algo así, pero puede ocurrir, en mi caso no ocurrió, sino al contrario, esos mayores me abrieron, me franquearon la puerta y yo accedí por ella y seguí mi camino siempre llevado de la mano de mis maestros, que me dieron su orientación y su consejo a lo largo de muchos años. Con el tiempo esos maestros desaparecieron del horizonte físico pero nunca han desaparecido del horizonte moral, de mi pensamiento, de mi reflexión, de mis sentimientos. Están presentes todos y cada uno de ellos. Ahora estamos llevando a adelante esta conversación en un auditorio que lleva el nombre de uno de mis maestros, Antonio Martínez Báez, que fue mi profesor de Derecho Constitucional en el doctorado en Derecho y que era un eminente constitucionalista, pero aparte de él puedo citar a muchos más.

AUB: Muchas gracias Doctor, en ese mismo sentido me gustaría ahora sí, entrar ya en el tema de alguno de estos grandes maestros que influyeron profundamente en su formación o en su caso también podrían ser autores quienes hayan determinado en algún momento su pensamiento, que hayan dado un vuelco ideológico ¿Alguno que pudiera comentarnos?

SGR: Que bueno que plantea la pregunta de esta manera. Créame que a veces uno sigue la enseñanza de un profesor en la catedra 
o eventualmente fuera de la catedra, pero también en ocasiones sin conocer personalmente al docente uno puede recibir la influencia, la enseñanza a través de las lecturas de obras, a través del pensamiento escrito o expresado de alguna otra forma por un gran catedrático. Guando yo ingrese al primer año en la carrera en Derecho tuve un excelente profesor en Introducción al Estudio del Derecho, el profesor Juan Bremer, que era un ilustre abogado, postulante eminente, pero que al poco tiempo tuvo un problema de salud muy severo que le obligó a retirarse de la catedra temporalmente por lo menos. Entonces, ante esta situación yo debí elegir a otro profesor para la clase de Introducción al Estudio del Derecho y viendo la relación de profesores que estaban impartiendo la clase encontré a uno que gozaba de gran fama, y que era uno de los profesores más prestigiados en esa disciplina. Me refiero a Don Eduardo García Máynez. Así que me fui a la catedra de Don Eduardo García Máynez, cambié incluso de horario porque yo estaba en el turno de la mañana y pase al turno vespertino, y me desempeñe todo ese año como alumno de García Máynez, y lector de su obra "Introducción al Estudio del Derecho", la cual es probablemente la obra de un jurista mexicano más publicada y más leída dentro y fuera del país. Tuve otros profesores muy apreciables en el primer año de la carrera de la Facultad. Algunos han dejado huella por su obra escrita. Recuerdo que tuve un maestro eminente de Sociología del Derecho, Don Juan Pérez Abreu de la Torre, quien no fue tratadista, lamentablemente, fue un hombre muy sabio, un profesor ilustre. Pase al segundo año, y estoy mencionando etapas porque sé que no hay tiempo para muchos detalles, y ahí me encontré con el primer curso de Derecho Penal, la parte general de Derecho Penal ¿Quién sería mi profesor? Pues elegí a Don Raúl Carrancá Trujillo, autor de la primera obra completa, panorámica de Derecho Penal, que se había hecho en México bajo el imperio de la legislación penal de 1931. Era un maestro muy competente, muy erudito y un hombre de bien, un hombre bueno que también fue generoso conmigo, me 
tendió la mano y yo seguí su curso de Derecho Penal con enorme interés. Bueno, sigamos adelante, vayamos a otra etapa. Cuando llegue a tercer año, cursé Derecho Constitucional con Don Mario de la Cueva, profesor eminente que ha dejado huella en la historia de la Facultad y de la Universidad. Fue mi profesor de Derecho Constitucional y también seguí su curso con enorme interés y con avidez. Ahora me viene a la memoria que también estudié con Don Eduardo Pallares, uno de los tratadistas más completos que hemos tenido en materia procesal, hijo de don Jacinto Pallares, él fue un hombre de gran prestigio y alcurnia, hombre muy culto, melómano, conocedor de la filosofía, música, letras. Más adelante, tuve un maestro verdaderamente decisivo en mi formación como estudiante y estudioso del derecho, que fue don Niceto Alcalá Zamora, quien formaba parte del grupo de profesores españoles migrantes, los llamábamos refugiados, que habían llegado a México en la circunstancia de la guerra civil española. Él había transitado de España a Argentina y luego vino a México, era un gran catedrático de Derecho Procesal, para mí fue de Derecho Procesal Penal, que luego sería la materia de mi predilección. Entonces, recibir enseñanzas de Don Niceto y el apoyo que sentía en él invariablemente para mi evolución y definir mi rumbo hacia la catedra y la investigación. En aquellos tiempos también fui alumno de Don Cesar Sepúlveda que sería director de la Facultad de Derecho y me invitaría más adelante a ser profesor. Otro maestro eminente, decisivo en mi vida, quien dejó una profunda huella en mi existencia y en mi formación, fue Don Alfonso Quiroz Cuarón, quien era criminólogo y formador de profesionales. Formó generaciones de penalistas, criminólogos, penitenciaristas, y a mí me apoyo en mi propio desarrollo, en mis actividades de trabajo inclusive, en el ámbito penitenciario, en el ámbito criminológico. Recurrí a él constantemente. Tenía una gran fama, un gran prestigio incluso fuera del país, su nombre abría puertas y a mí me abrió muchas puertas en México y fuera de México. Cuando llego el momento de que yo avanzara en mi carrera 
penitenciaria en el Gentro Penitenciario del Estado de México creí, indispensable ponerme en contacto con algunos penitenciaritas fuera del país que me pudieran orientar y auxiliar con su experiencia, y Don Alfonso me presento con personajes del penitenciarismo fuera de México, en Argentina, Perú, Brasil, en fin, en otros países. Gracias a él pude recibir estas enseñanzas. Más adelante, en quinto año, estoy tratando de ser muy específico en cuanto a algunos profesores pero fueron muchos los que me ayudaron y debo agradecer, más adelante fue mi profesor Don Luis Recasens Siches, otro refugiado español, prominente maestro, filósofo del Derecho y tratadista. Asimismo debo reconocer y recordar también a Don Emilio Rabasa, quien seria canciller de la República, y en ese tiempo era secretario del posgrado y mi maestro de Teoría del Estado, pude considerarlo también mi amigo, generoso.

En fin, corro el riesgo y no quisiera caer en él, pero claro que lo estoy enfrentando, de no mencionar a todos, porque fueron muchos aquellos de los que yo recibí orientación y consejo. En el posgrado se repitió la presencia de alguno de estos profesores, como Alcalá Zamora, Quiroz Cuarón, pero además se agregó Celestino Porte Petit, quien fuera otro gran penalista, maestro emérito Don Octavio Hernández, constitucionalista, amparista, Don Rafael Rojina Villegas, tratadista de derecho civil y Rafael de Pina, también profesor español, en fin, varios más, todos ellos personajes de primer nivel en la historia del Derecho Mexicano de esa época, quienes fueron formadores de los profesores de ahora, y además grandes personajes en mi propia vida. Los recuerdo con emoción y gratitud.

AUB: Le agradezco los bellos recuerdos que nos ha compartido, me gustaría saber si ¿hay algún jurista, algún autor actualmente que le llame la atención?, alguien a quien usted siga actualmente en temas teóricos o prácticos ¿Existiera alguno actualmente que pudiera referirnos?

SGR: Por supuesto, hay muchos, tenemos una pléyade de tratadistas, profesores, catedráticos de enorme valía. Quienes fueron mis 
maestros ya no se encuentran físicamente presentes, prácticamente todos se han ausentado físicamente, pero yo mencionaría simplemente como ejemplo a un gran jurista eminente, de cuyo talento, de cuya ciencia hemos abrevado y lo seguimos haciendo los juristas mexicanos, me refiero al profesor Héctor Fix Zamudio que fue director del Instituto de Investigaciones Jurídicas, investigador emérito, quien ha sido colmado de honores y de preseas y de doctorados donde quiera. Es otro de esos personajes que ha tenido una poderosa influencia en la formación del Derecho Mexicano, no solamente en la cátedra como profesor de miles de estudiantes sino en la formación de instituciones. A Don Héctor Fix Zamudio le debemos progresos enormes en materia de derechos humanos por ejemplo, el ombudsman, instrumento de derechos humanos que actualmente tenemos en México bajo el nombre de Comisión de Derechos Humanos es una creación de Fix Zamudio. Fue uno de los estudiosos adelantados en la materia de ombudsman, secundado después por uno de sus alumnos dilectos Jorge Carpizo. Trabajaron juntos en la creación de la Defensoría de los Derechos Universitarios que fue un embrión del ombudsman mexicano, entonces merece una referencia muy especial Fix Zamudio. Además, puedo mencionar que él fue uno de los factores para la creación de seminarios, cátedras, renovación de muchos estudios, creación del Consejo de Judicatura. Milito muy activamente para que se generara ese Consejo y lo consiguió a través de reformas constitucionales. Así pues, que si usted me pregunta, como lo está haciendo, por algún maestro que esté vigente, que esté vivo, al cual podamos recurrir como ejemplo y con gratitud los abogados mexicanos, pues yo cito a la cabeza a don Héctor Fix Zamudio.

AUB: Creo que no está errado, el Doctor Fix Zamudio es un gran referente mexicano. Doctor, ahora pasando ya a como usted se mira ¿Usted se consideraría penalista, internacionalista, digamos dentro del área de Derechos Humanos, procesalista, constitucionalista? Lo pregunto porque tiene una cantidad de obras tan importantes 
en diferentes áreas, he de decir también, que todas concatenan en algún sentido pero me llama la atención y me pregunto ¿cómo se evalúa usted?

SGR: Bueno, me miro como abogado, como jurista que ha tenido la fortuna, por las vicisitudes de la vida, de asomarse con gusto, con agrado a diversas áreas del conocimiento y la práctica jurídica; me inicié en los quehaceres penitenciarios, lo he dicho, luego en los penales, el procedimiento penal, pero también en el tema de los derechos humanos y particularmente en el tema del Derecho Internacional de los Derechos Humanos, que no es materia distanciada del Derecho Penal o del Derecho Procesal, están entrañados; los Derechos Humanos tienen escenarios difíciles, críticos en el ámbito penal, entonces hay una vinculación muy cercana entre uno y otro, esto me ha llevado, por lo tanto, de lo penitenciario a lo penal, a lo procesal, específicamente procesal penal; no he incursionado en otras disciplinas del proceso salvo el procesal internacional.

No me he visto forzado a escribir, me gusta hacerlo ya que también es parte de mi vocación, la forma en que yo me expreso a través de la cátedra, pero también a través del trabajo escrito, así que no necesariamente me quisiera yo definir como penalista o procesalista o internacionalista, sino como un jurista modesto que ha tenido la suerte de salir al balcón y ver desde ahí transitar varias disciplinas, varias actividades y tratar de atenderlas y de servirlas.

AUB: En este mismo sentido como usted ya lo ha dicho, tiene muchas obras, sus obras y su pensamiento han sido referentes para nuestro país así como tanto para el extranjero ¿Cuál considera usted que es su libro más representativo? Digamos podría ser tanto el más reciente como el primero de ellos, pero ¿alguno en particular que sienta que es un libro donde se identifica?

SGR: Bueno, mire usted, como he trabajado en la producción de varios libros en distintas disciplinas, no me resulta fácil dirigirme a cierto libro o ciertos libros con predilección porque en todos he puesto parte de mi vida, en todos he integrado mis meditaciones, 
mis experiencias, pero si se me apremia para que mencione alguna obra en particular, yo probablemente mencionaría alguna o algunas de las más recientes simplemente para no irme al pasado remoto, mejor el pasado reciente, el pasado inmediato. Mencionaría yo, por ejemplo, dos obras del pasado reciente e inclusive de la actualidad, una de ellas es "La reforma penal constitucional ¿Democracia o autoritarismo?" que es un libro en el que paso revista, desde mi propia perspectiva, a la reforma penal constitucional de 2008, una reforma muy grande, grande de volumen y ojala que también en resultados, bueno, este libro me resulta interesante dentro de mí propia línea de investigación de docencia y de difusión, y otro más reciente dentro de esa misma línea que se llama "El procedimiento penal" que salió apenas el año pasado y que tiene el subtítulo de Constitución y Código Nacional, que analiza los temas penales, procesales penales en la Constitución Política de los Estados Unidos Mexicanos y particularmente en el Código Nacional de Procedimientos Penales, que es un ordenamiento relativamente nuevo con una serie de figuras interesantes, novedosas y que forma parte de la fragua actual del Derecho Mexicano, particularmente en el ámbito de la procuración y administración de justicia. Hay otra obra que me resulta de alguna manera simbólica de quehaceres permanentes, que se llama "Los personajes del cautiverio", que es un libro anterior, editado hace algunos años. "Prisiones, prisioneros y custodios" es su subtitulo. En esta obra deposito muchas de mis reflexiones en materia penitenciaria, y ya que hablo de esa materia agregaría todavía una obra, sin querer abrumarle con muchas citas, que se llama "El final de Lecumberri", porque fui director de ese reclusorio cuando se llamó "El palacio negro", que hoy es el Archivo General de la Nación. En los últimos tiempos de su función como cárcel preventiva de la Ciudad de México, me correspondió abrir esa cárcel porque estaba cerrada y la abrimos cuando estuvo ya sin población para convertirlo en un organismo totalmente distinto, esto último ya no me tocó, lo que me tocó fue el cierre o la apertura 
de ese palacio negro con una tradición sombría. A ese momento de mi vida, de mi experiencia, me refiero en este pequeño libro que se llama "El final de Lecumberri", que yo quisiera poner en manos de todos los penitenciaristas para que compartieran las experiencias de su viejo amigo y fueran incubando sus propias experiencias.

AUB: Ahora Doctor, adentrándonos en su ejercicio profesional en particular, usted es muy reconocido en los ámbitos en los que hemos mencionado, el procesal, el constitucional, penal en sí mismo pero me voy a referir a uno en el que estoy segura usted tendrá muchas citaciones, me refiero al ámbito del derecho internacional, en particular de los Derechos Humanos, en este sentido ¿Considera usted que las generaciones actuales tienen una mejor comprensión acerca del actuar de la Corte Interamericana de Derechos Humanos en comparación con las generaciones pasadas? Es decir que los derechos humanos han impregnado con cierta fuerza el pensamiento jurídico desde esa misma medida que ha generado cambios en nuestra sociedad o, ¿nos vemos en el mismo momento en que ha iniciado este gran movimiento?

SGR: Yo creo que ha sido y así está siendo en este momento, no solamente en lo que se refiere a los jóvenes abogados en formación o los abogados recién egresados de la carrera, sino quizá también en lo que toca con algún alcance a la sociedad en su conjunto. Quisiera mencionarle o recordarle que en la etapa de mis propios estudios de licenciatura no teníamos una materia llamada Derechos Humanos, no es que no tuviéramos una idea acerca de que eran los derechos humanos o que no hubiera tratadistas sobre derechos humanos, pero nuestra materia no se denominada así, sino "Garantías y Amparo", era una materia que cursábamos en el cuarto año de la carrera y entonces estábamos muy familiarizados con el concepto de garantías individuales y no tan impregnados de la noción de los derechos humanos, y por supuesto tampoco existían las instancias internacionales que existen actualmente. No existía en modo alguno la Corte Interamericana de Derechos Humanas que tiene 
40 años de haber sido instalada y estar funcionando. Mis estudios como licenciado en Derecho tienen mucho más de 40 años, por lo que no había nada de esto. Creo que al tomar presencia los tratados internacionales de Derechos Humanos al calor de muchos sucesos nacionales e internacionales, se planteó y se activó el interés por los derechos humanos, no solo por las garantías individuales, sino por lo que esta atrás de las garantías o debajo de ellas, en el cimiento de las garantías, que son los derechos humanos, han adquirido una presencia relevante. Se han hecho modificaciones, cambios normativos en el peldaño constitucional, en el peldaño secundario y también en la impartición de justicia, en las políticas públicas que tienen que ver con los derechos humanos. Hoy tenemos una sociedad, aunque muy golpeada y en muchos aspectos muy maltratada, pero una sociedad más consciente de que existe esto que llamamos derechos humanos y que es importante y necesario conocerlos y reclamarlos, y creo que tenemos un poder público que a pesar de todas sus fallas va a cobrar una consciencia cada vez mayor, de que esos derechos de los individuos, de los ciudadanos, de las personas, generan obligaciones, deberes precisos, inmediatos, para quienes detentan el poder, quienes han sido investidos con facultades o atribuciones de carácter público, entonces, estos funcionarios públicos creo yo que van estando cada vez más conscientes de sus deberes. Todavía no son muy cumplidores, pero bueno, lo son más quizá de lo que eran antes, por lo menos eso es lo que yo esperaría. Respondiendo a su pregunta y tratando de ser más conciso, sí, ha habido una presencia mayor del concepto, del fenómeno de los Derechos Humanos. Ya es algo que traemos entrañado, ya es algo de lo que se habla constantemente, no sé si se practica constantemente, pero se habla constantemente, y eso no ocurría antes, ahí ha habido un giro de 180 grados. A aquello que estaba en la oscuridad, en la penumbra, que no acababa de nacer, ha nacido, florecido, está a la vista y ya podemos invocar y lo hacemos todos los días, en esta Facultad y en otros lugares, ya podemos invocar los derechos fundamentales 
que nos asisten, los derechos humanos y sabemos que hay tribunales en la República, tribunales de amparo desde luego, cuyo fin es la protección de los derechos, que existen instancias como la Comisión Nacional, las Comisiones Estatales que tienen una atribución similar y que hay finalmente instancias internacionales que también están atentas a la preservación de los derechos humanos: Comisión Interamericana, Corte interamericana y otras instituciones dentro del sistema universal de protección de los derechos humanos. Entonces aquí si ha habido un giro muy importante y espero que logremos acentuar ese giro más y más, sobre todo al calor de algunas modificaciones de nuestra normativa, por ejemplo la reforma de 2011 en materia de derechos humanos, el gran cambio que se impregnó a la Constitución con el nuevo texto del artículo $1^{\circ} \mathrm{de}$ nuestra ley fundamental.

AUB: De acuerdo Doctor, ahora bien, en algunos casos incluso la reticencia de algunos Estados para adoptar las resoluciones emitidas por la Corte Interamericana de Derechos Humanos, ¿considera usted que tenemos alguna garantía sobre la integridad del sistema interamericano?

SGR: Garantía absoluta solo la que nosotros seamos capaces de formar. El sistema interamericano está garantizado por la voluntad política que yo espero se mantenga con un ingrediente, un componente ético de los Estados que conforman el sistema interamericano, la organización de los Estados Americanos. A veces hay quebrantos, hay fracturas de este gran conjunto, algunos Estados de este sistema no han reconocido la Convención Interamericana y mucho menos han reconocido la competencia de la Corte. Es lo que sucede, para citar dos casos notables, con los Estados Unidos de América y Canadá, así como algunos países del Caribe. En los países de América Latina también ha habido vicisitudes muy serias y en ocasiones tendencia a retraerse del sistema interamericano, notoriamente en el caso de Venezuela, pero no solamente es el caso de Venezuela ha habido movimientos en esta dirección. Por fortuna 
no se ha fracturado, no se ha vulnerado lo esencial o fundamental del sistema interamericano y yo diría que el caso de México, específicamente después de una larga etapa de cierta distancia, de cierta lejanía entre el Estado mexicano y el sistema interamericano de protección de los Derechos Humanos, no animosidad, no contienda, pero si lejanía, el Estado mexicano reaccionó al final del siglo XX y expresó su voluntad de militar con claridad como parte de la Convención Americana y sujeto de la jurisdicción contenciosa de la Corte Interamericana. Esta decisión del Estado Mexicano se ha mantenido, no fue sencillo que se adoptara. Creo yo que aquí ocurre lo que suele ocurrir en cualquier Estado, ningún Estado es monolítico, en el seno de los Estados hay corrientes en un sentido y en otro y se da una dialéctica. A veces se acentúa mucho la dialéctica que existe entre sectores del pueblo, de la sociedad civil, como la nombramos, y autoridades públicas, pero también en el seno de las autoridades públicas o Estado, hay corrientes distintas que entran en tensión, hay una dialéctica adentro del aparato gobernativo, adentro del aparato estatal, no solamente frente al aparato estatal y por parte de la sociedad, sino adentro, tendencias progresistas y tendencias regresivas, finalmente predominan unas u otras. En México creo yo han predominado, hasta el momento, las tendencias progresistas aunque con un paso mesurado, con un paso que quisiéramos fuese más rápido y más profundo, pero México no ha expresado reticencias formales, reservas formales frente al sistema interamericano, ni se ha negado a dar cumplimiento a las decisiones de la Corte Interamericana, en ocasiones ha sido lento ese cumplimiento, muy complicado pero no ha habido rechazo, en otros países eventualmente sí ha habido situaciones de rechazo e incluso de conflicto, que a veces se han superado y en otras ocasiones no ha sido posible superarlas. En fin, tenemos un panorama heterogéneo, pero dentro de este panorama me parece que la Corte y el sistema en su conjunto siguen avanzando con mucho esfuerzo, porque finalmente el tema de los derechos humanos no es un tema sencillo 
y tiene que ver con la preservación del ser humano frente al poder público y el poder público es Leviatán, que tiende a ser majestuoso, monstruoso, y a excederse. Cuando no hay corrientes democráticas prevalecientes, los derechos humanos padecen y las instancias tutelares de los derechos humanos menguan su entidad, su señorío y a veces pasa esto, en este mundo revuelto en el que estamos inmersos, me refiero al mundo entero. Hay corrientes que ven con renuencia y con escepticismo, hasta con animosidad, a los derechos humanos, porque sienten que son un obstáculo para el ejercicio del poder, nosotros debemos insistir, con un signo humanista y democrático, en la necesidad de preservar los derechos humanos frente al poder público, para eso se concibieron esos derechos.

AUB: Adentrándome un poco más en este sentido y ya en el ámbito muy nacional, Doctor, ha habido una discusión en torno al orden, la fuerza que deben tener los Derechos Humanos en el orden del Estado Mexicano y también la discusión acerca de si estos deberían estar subordinados a la Constitución o si la Constitución tendría que estar subordinada a los Derechos Humanos, es decir ¿Cómo se debería entender lo establecido en el artículo 133 constitucional? y que algunos identifican como el bloque de constitucionalidad ¿Cuál es su perspectiva en relación a este artículo 133 constitucional? ¿Cómo se debe entender?

SGR: Greo que el tema se ha estado ventilando en México intensamente, y en muchos países de América. Varios han legislado también incluso a nivel constitucional, estableciendo el vínculo, el puente entre el derecho nacional y el derecho internacional y creando situaciones de compatibilidad entre los derechos previstos en los tratados internacionales y los previstos en las Constituciones nacionales, inclusive colocando en el rango constitucional a los derechos contemplados en los tratados internacionales, como fue el caso de Argentina con una gran reforma a la Constitución en 1994. En el caso de México tenemos dos textos sobre esta materia, que son el artículo $133 \mathrm{y} \mathrm{el} \mathrm{artículo} 1^{\circ}$. El 133 es un texto antiguo que toma- 
mos incluso de la Constitución de los Estados Unidos de América y se refiere a la ley suprema de la unión, los tratados que se ajusten a ella, las leyes emanadas de ella. Por otra parte, el artículo $1^{\circ}$ utiliza otras expresiones porque coloca en el más alto rango a los derechos previstos en los tratados internacionales. Sin embargo, lo anterior deja abierta la puerta, como lo ha sostenido alguna jurisprudencia, para que prevalezcan ocasionalmente limitaciones o restricciones a los derechos en la medida en que la Constitución misma establezca estas restricciones o limitaciones, ahí surge la letra y el espíritu del artículo 133. Yo que soy devoto de la idea de los derechos humanos para todos con la mayor intensidad, con la mayor profundidad del llamado principio de pro homine, creo que lo que debe prevalecer no es el Derecho constitucional o el Derecho internacional sino la dignidad humana, lo que más beneficia y proteja al ser humano, se establezca como se establezca, en la Constitución o en el Derecho Internacional o en otros ordenes normativos. Me parece que esto debe prevalecer y predominar y que está en el ánimo profundo de nuestra Constitución, en las Constituciones modernas y del sistema convencional de los Derechos Humanos, pero reconozco que hay ahí un problema, hay un problema de interpretación, de lectura del texto supremo, hubiera sido muy deseable, como exprese en un libro que elaboré junto con Julieta Morales sobre la reforma en materia de derechos humanos, la reforma de 2011, que al crearse el nuevo texto del artículo $1^{\circ}$ se modificara, se revisara el articulo 133 y que los términos de ambos fueran compatibles, porque hoy tenemos dos textos de dos etapas distintas de nuestra historia, uno que traemos de más de un siglo atrás, y otro que tenemos desde hace una década. Ahí hay una antinomia que pudimos ahorrarnos si hubiéramos revisado el 133. Estimo que en nuestro futuro se encuentra un reconocimiento sin complicaciones mayores, un reconocimiento franco y claro de que lo que debe prevalecer es lo que más beneficie a la persona, sea en la Constitución, sea en el Derecho internacional, porque el centro de nuestra preocupación, de nuestras normas, de 
nuestras decisiones políticas fundamentales reside en la tutela del ser humano y de su dignidad, no en la preservación de la supremacía internacional o constitucional. Ese es mi punto de vista. El bloque de constitucionalidad nuestro se integra ya, aunque a veces preferimos hablar de un parámetro de regularidad constitucional, pero es un bloque de constitucionalidad. Por algún motivo no hemos asumido la expresión, pero el bloque se encuentra integrado por el texto de la Constitución y por otros textos que tienen un rango constitucional, como son los tratados de derechos humanos o las normas sobre derechos humanos contenidas en los tratados internacionales, ese es nuestro bloque de constitucionalidad. Hace algunos años tampoco se hablaba de un bloque de constitucionalidad, es una expresión, una figura que nos resulta todavía novedosa, no acabamos de utilizarla en plenitud, pero ahí está ya desde hace muchos años en la doctrina francesa y adoptada por la doctrina y la legislación de otros países. Ese es nuestro bloque.

AUB: Gracias Doctor, quiero hacer una pregunta un poco más especifica que me ha surgido ahora que hemos estado conversando, en México además de todos los grandes retos que tenemos, jurídicos, antinomias, lagunas, muchas cosas por resolver y que seguramente el órgano jurisdiccional revisará y resolverá, yo quiero preguntarle en torno a algo que también ha estado en discusión hace algunos años con cierta fuerza. Me refiero a la consideración de México como un Estado fallido, en algunos casos algunos autores han considerado que existe un Estado fallido debido a la falta de legalidad, de rendición de cuentas, de impunidad y corrupción estructural, es decir, ¿Hasta dónde podemos considerar que México es un Estado fallido? Y ¿cómo podríamos en caso de no ser transitar hacia un verdadero Estado Constitucional Democrático de Derecho?

SGR: Bueno, aquí habría que deslindar el alcance del concepto de Estado de Derecho, por una parte y Estado fallido, por la otra. Es evidente que se pueden conectar ambos conceptos, pero expresan situaciones que vale la pena analizar en forma separada. El 
estado de Derecho, al que usted se acaba de referir, no es solamente un Estado de orden público en el que prevalezca la paz y eventualmente el silencio, la tranquilidad de los ciudadanos. Un Estado de Derecho, un Estado Constitucional de Derecho, democrático de Derecho, social de Derecho, con todas las calificaciones que se han ido incorporando en esta expresión, es aquel en el que rigen derechos fundamentales de los individuos, de los ciudadanos, digo ciudadanos en un sentido muy amplio, y se cumplen los deberes correspondientes por parte de las autoridades públicas. Esto es, en síntesis, un Estado de Derecho, y si queremos hablar de un estado de derecho democrático habría que preguntarnos y responder qué es la democracia y entonces invocaríamos el artículo $3^{\circ}$ de nuestra Constitución, democracia como sistema de vida. Ese es el conjunto de datos a considerar para entender que debo ser un Estado de Derecho, democrático, social en el cual exista plenitud de práctica de los derechos humanos y plenitud de cumplimiento de obligaciones de los funcionarios públicos ¿Hemos logrado esto con plenitud? No, realmente no, sería ingenuo decir que sí, es un largo camino que hemos estado recorriendo desde hace muchos años y que no hemos agotado. A veces ha habido pasos adelante, a veces atrás o en dirección lateral, pero estamos todavía lejos de conseguir tener o ser un verdadero Estado de Derecho. Ahora el tema del Estado fallido. A veces decimos que porque México no logra ser un Estado de Derecho es ya un Estado fallido, es decir, ha fallado como Estado y por lo tanto es un Estado fallido; yo no me atrevería a calificar todavía y créeme que digo todavía con una gran cautela y con un gran temor, todavía al Estado mexicano como un Estado fallido. Chomsky ha considerado que un Estado fallido es aquel en el que el poder público o la estructura del Estado no logra garantizar la seguridad de los habitantes, no logra proveer a los habitantes de verdaderas condiciones de seguridad y que a la postre se convierte en un peligro, en un problema inclusive para otros estados. A esto, en términos generales y sucintos, califica ese notable tratadista nor- 
teamericano como "Estado fallido". Yo no creo que seamos todavía un Estado fallido, pero sí creo que tenemos grandes fallas, vamos a ponerlo de esa manera: estamos transitando un camino colmado de riesgos, en el que no hemos acertado a dar a los ciudadanos de la Republica las condiciones de seguridad mínima que todos merecemos, estamos asediados por la ilicitud, el crimen, la corrupción, la impunidad. Creo que esto es algo que se dice a voz sin cuello y se reconoce plenamente, lo reconoce nuestro congreso, lo reconocen los tribunales, lo reconoce el poder ejecutivo y no se diga la sociedad, todos lo reconocen. En ese sentido hay muchas fallas que debemos resolver y apurarnos en la solución de estas fallas, sin embargo insisto en que aún no me atrevo a calificar a México como un Estado fallido en la forma o el alcance de otros Estados en el mundo que se han desorganizado en forma total, en los cuales hay genocidios o situaciones masivas de vulneración sistemática realizada por las propias autoridades de los derechos humanos, de desconocimiento de los deberes elementales del poder público. Una situación así no existe en México y debemos empeñarnos en que no exista y desde luego generar las condiciones para que no lleguemos a semejante colmo a partir de un diagnóstico honesto, objetivo y veraz de la situación en la que nos encontramos. Si todos los días negamos que hay problemas, si todos los días decimos que estamos avanzando a grandes trancos en la solución y que aquí no pasa nada, creo que corremos el riesgo de que pasen muchas cosas de las que están pasando.

AUB: De acuerdo Doctor, ¿algo que pudiera cambiar realmente la realidad mexicana podrían ser los derechos humanos?

SGR: La práctica de los derechos humanos. El mero catálogo de estos derechos no es por sí mismo un dato mágico para la modificación de nuestra vida colectiva o individual. Si estos derechos que están estipulados en los tratados internacionales y en la propia Constitución y que son muy numerosos, no se observan puntualmente se convierten en retórica, demagogia. Prácticamente lo que 
tenemos que lograr es su observancia fiel y franca, y para ello una actitud de exigencia por parte de la sociedad, del pueblo, hablamos de sociedad civil yo hablaría más bien del pueblo en su conjunto, exigencia formal y franca, intensa, reiterada, no exigencia violenta pero si exigencia tenaz de la observancia de los derechos humanos; y por parte del poder público una actitud comprometida con los derechos fundamentales y con la preservación de la democracia y del Estado de Derecho. Me parece que hay deficiencias en ambos campos, en el societario, de exigencia del respeto a los derechos, a veces hay un poco de condescendencia o de retraimiento, olvido, y en el caso del poder público, hay negativa franca al cumplimiento y planteamiento muy peligroso de falsos dilemas. Me explico: ¿qué es esto de los falsos dilemas? En condiciones como éstas, de inseguridad pública, de incremento de la delincuencia y de graves condiciones de vida, hay la tentación por parte de algunas instancias a atribuir todo esto a los derechos humanos y decir que los culpables son los derechos humanos. Sí quieren que haya observancia de los derechos humanos, renunciemos a la seguridad pública o a cierta porción de seguridad y si quieren seguridad pública mitiguemos los derechos humanos. Este es un falso dilema que se plantea constantemente, sobre todo desde instancias incumplidoras del poder público, es muy peligroso porque nos coloca frente a una disyuntiva falsa. Me parece que los ciudadanos de una comunidad democrática como queremos que sea México, podemos y debemos exigir ambas cosas, por una parte, tener Derechos Humanos que se observen, se cumplan, se respeten, se garanticen y, por otra, tener seguridad, porque dicho sea de paso, la seguridad es un derecho humano. Desde la Declaración Francesa de los Derechos del Hombre y del Ciudadano se entiende que la seguridad es un derecho humano, un derecho natural del ser humano. Podemos y debemos tener ambas cosas; que no nos planteen alternativas o disyuntivas, que no nos digan que por una situación de emergencia o de gravedad en las condiciones de vida vamos a tener que moderar la exigencia de de- 
rechos fundamentales y retirar algunos o condicionarlos, este es un peligro muy grande que corren las sociedades como la nuestra que enfrentan condiciones de criminalidad exacerbada. Creo yo que eso lo estamos viviendo y hay que salir al paso.

AUB: ¿Considera usted como experto penalista que ha sido un acierto o probablemente una idea que no tiene mucho sustento la creación de la Guardia Nacional?

SGR: Me parece que frente a la situación que estamos enfrentando, frente a este auge de la criminalidad y la inseguridad era necesario y, lo sigue siendo contar con mecanismos, con herramienta adecuada por parte del Estado para enfrentar esa criminalidad exacerbada, desmedida que nos asedia y nos daña todo el tiempo. Ahora bien, creo que hubiera sido deseable que se meditase con más cuidado, con mayor reflexión, con mayor detalle cuáles pudieran ser estas herramientas adecuadas. Lo que se nos está dando a través de la Guardia Nacional es una corporación, una institución con fuertes rasgos militares recubierta con un manto civil pero con fuertes rasgos militares. Esta Guardia Nacional es una cosa bien distinta de la que estaba alojada en nuestra Constitución desde hace más de un siglo. Al crearse esta nueva corporación con elementos militares y civiles, pero predominantemente los militares, se ha dejado de lado algo que es de enorme importancia y que parece olvidado, que es la necesidad de contar con una verdadera policía ordinaria. Hay centenares de policías en este país, de individuos que ejercen funciones de policía, y hemos olvidado que ahí hay áreas de incompetencia y de falta de idoneidad terribles y que necesitamos reconstruir la policía, pero en lugar de esforzarnos en reconstruirla generamos o engendramos una criatura nueva que se llama Guardia Nacional, con una gran prisa, con una gran celeridad, con componentes civiles y militares y constitucionalizamos en un artículo transitorio del Decreto de reforma constitucional, el mismo que crea la Guardia Nacional, la presencia de las fuerzas armadas en materia de seguridad pública durante cinco años. Así hemos generado un heterogé- 
neo conjunto de medidas entre las cuales no destaca la recuperación de la policía, sino la Guardia Nacional y vemos que en el momento de realizar esta charla amable a la que ustedes me han hecho el favor de convocarme, se dice que ya estaba operando la Guardia Nacional. Guando todavía no entran en vigor ni se acaban de expedir las normas reglamentarias de la Constitución, estamos viendo en fotografías y en películas a elementos de las fuerzas armadas que ostentan un gafete que dice GN (Guardia Nacional) como si ya existiera una Guardia Nacional, estamos viendo que no ha habido todavía un sistema eficaz y amplio de reclutamiento de efectivos de la Guardia Nacional y de preparación de sujetos efectivos. Estamos actuando bajo la presión de las circunstancias con gran prisa, con enorme angustia que es una angustia compartida por la sociedad que se duele de las condiciones de inseguridad pública. Ojala que en este andar tan apresurado no cometamos errores graves que pudieran deslizarse no solamente en la forma de aplicar las reformas constitucionales sobre Guardia Nacional, sino también en las otras reformas que han ocurrido últimamente y que tienen que ver con la privación de dominio de ciertos bienes, y particularmente con la prisión preventiva oficiosa; hemos ampliado las hipótesis de prisión preventiva en lugar de disminuirlas y racionalizarlas que sería lo consecuente con la reforma de 2008 que establece la presunción de inocencia, es decir, estamos, si usted me permite la expresión, "enredados" en soluciones parciales, contradictorias, no suficientemente exploradas. No parece haber una verdadera carta de navegación que nos diga este es el rumbo, el camino que hemos pensado con muchísimo cuidado. Yo no le atribuiría esto como culpa a la administración que acaba de asumir la responsabilidad política y jurídica del país, bueno, política más que jurídica, la jurídica la tienen muchas autoridades; no lo podría yo confinar en estos meses ni en estos años, ya que es algo que ha ocurrido y no me gusta estar mirando siempre para atrás, echando culpas para allá y halagos para acá. El hecho es que estamos sumergidos en esta circunstancia 
azarosa y peligrosa, en la que debemos tener infinito cuidado al tratar de resolverla, no es fácil, no es de un día para otro. Nuestros descuidos tradicionales están teniendo un alto precio, pero no vaya a ser que al alto precio de descuidos tradicionales tengamos que agregar el elevado precio de nuestros errores actuales.

AUB: Muy de acuerdo Doctor, yo tengo una cantidad enorme de preguntas que por supuesto quisiera plantear pero no quisiera pecar de exceso, porque además me gustaría que en alguna otra ocasión me aceptara otra invitación, entonces, quisiera hacerle una última pregunta si me lo permite: como profesor emérito de esta Universidad ¿cuál sería el llamado que le hace a esta comunidad jurídica? especialmente por los nuevos retos a los que se enfrentan los juristas ¿Qué es lo que nos puede sugerir?

SGR: El llamado que yo le haría a los jóvenes estudiantes, a los juristas, mis colegas, es el mismo que me hago a mí mismo, es trabajar con esmero, trabajar con profundo compromiso, seguir estudiando, seguir ponderando, reflexionando, buscando soluciones razonables, racionales, a los problemas que nos aquejan, con profundo patriotismo, con objetividad, con una conducta ejemplar. Es lo que se puede sugerir, y en todo caso esto es algo de lo que no debemos prescindir. Guando encontremos problemas hay que denunciarlos, señalarlos, levantar la voz, cuando veamos que hay inobservancia, levantar la voz para exigir nuestros derechos y el cumplimiento de los deberes de los individuos miembros de la sociedad, así como del poder público. Creo que esto vale para el conjunto de la Nación, pero vale específicamente para los estudiantes, estudiosos o aplicadores del orden jurídico mexicano, para quienes tienen a su cargo la procuración o la impartición de justicia, porque en el caso de nosotros, abogados, existe un compromiso especial por cuestiones profesionales, por razones vocacionales, por expectativa social. Por supuesto algo similar se puede decir de ingenieros, médicos, profesores, normalistas, astrónomos o geólogos. Se puede decir esto de todos los integrantes de una sociedad, pero con énfasis 
particular en los abogados, en los juristas que han optado encausar su vida en el cumplimiento del Derecho, de la ley justa y yo no hago antinomias entre justicia y ley, que conste esto. Pretendo, que la ley sea justa y que si no es se modifique, no con un memorándum, sino de una manera formal a través de los campos adecuados, pero en fin, los abogados hemos elegido este camino entonces tenemos que transitar por él. Tenemos que acreditar la autenticidad de nuestra decisión vocacional y profesional para la que estamos más comprometidos que los practicantes de otras profesiones. Este es el llamado, pero no voy a decir que se lo hago solo a los jóvenes, también a mí mismo: seguir adelante con constancia hasta el último aliento, luchando por el Derecho, la lucha por el derecho según aquel librito famoso de Rodolf'von Ihering, que todos leímos: "La lucha por el Derecho". Esta es la tarea.

AUB: Doctor, muchas gracias por esta maravillosa entrevista. SGR: Muchas gracias. 